\title{
Hormone Replacement Preparation
}

National Cancer Institute

\section{Source}

National Cancer Institute. Hormone Replacement Preparation. NCI Thesaurus. Code C29731.

Synthetic female sex hormones mixture administered either orally or transdermally to maintain adequate levels of estrogen in women with diminished circulating sex hormones. Hormone replacement preparation is usually given to menopausal women to alleviate menopausal symptoms, including hot flashes, night sweats, irregular menstruation, fat redistribution, mood swings, sleep disorders, vag inal dryness and to prevent osteoporosis. The preparation usually contains conjug ated estrogens, estradiol, or estrone sulfate and a progesterone derivative, such as medroxyprogesterone, norgestimate or norethindrone, which is used to offset an increased risk of estrogeninduced endometrial cancer. 